\title{
SIMULATION AND VISUALIZATION OF WATER FLOW
}

\author{
František HROZEK, Branislav SOBOTA \\ Department of Computers and Informatics, Faculty of Electrical Engineering and Informatics, \\ Technical University of Košice, Letná 9, 04200 Košice, Slovak Republic, tel.: +421 55602 2563, \\ e-mail: frantisek.hrozek@tuke.sk,branislav.sobota@tuke.sk
}

\begin{abstract}
At present the problematic of floods is larger than ever because global warming, deforestation and other factors increase chance of flood creation. As prevention to floods, designing of many new anti-floods projects have been started. In the future, these projects will stop floods completely or at least reduce their consequences. Water flow simulation and visualization is an integral part of this process. Simulation is used for testing, if the project meets flood protection requirements. Visualization is used for presenting and helps investors and wide public to better understand these projects. Stereoscopic visualization can be also used, because displaying of outputs from simulation and visualization is important, too. This paper aims at fluid flow simulation and visualization software. Also aims at hardware that can be used for stereoscopic visualization.
\end{abstract}

Keywords: computational fluid dynamics, fluid flow simulation, fluid flow visualization, stereoscopic visualization

\section{INTRODUCTION}

Several floods hit Slovakia in recent years. Some of them were small and caused only small damage on human properties. But some of them were large and caused large damage, even some people were killed.

At present, designing of several anti-flood projects has been started. In the future, these projects will stop floods completely or at least reduce their consequences. Visualization and simulation of water flow is an integral part of these projects. Simulation on anti-flood barrier virtual model is used for testing, whether the newly proposed project satisfies the requirements for flood protection. Visualization is used for project presenting and helps investors and wide public to better understand the project, because not everyone knows how to read blueprints. Another important thing is how will be outputs from water flow simulation and visualization displayed. Nowadays the most used devices for displaying are monitors and projectors, but for the better impression a stereoscopic visualization can be used.

Simulation and visualization can be also used by flood crisis management, because fast and accurate information about flood spreading minimize damage on properties and human lives losses.

This paper aims at simulation and visualization software that can be used for water (or any fluid) flow simulation and visualization. It also aims at visualization hardware that can be used for stereoscopic visualization.

Paper is organized as follows. In section 2 are mentioned methods that are used in calculations for simulations and visualizations. Section 3 deals with the software that can be used for water flow simulation. In section 4 is mentioned a software which can be used for flowing water photorealistic visualization. Section 5 deals with stereoscopic visualization that can be used for displaying. Section 6 is about water inflow/drainage simulation program, which was developed at DCI FEEI TU of Košice. In section 7 are mentioned applications which use fluid flow simulations and visualizations. Section 8 summarizes information presented in the paper.

\section{USED METHODS}

Both visualization and simulation use laws of fluid mechanics [1] for realistic visualizations and physically accurate simulations (liquids, gases and plasmas belongs to fluids). Fluid mechanics is a part of physics that deals with fluid flow. Fluid mechanics can be divided into fluid statics, the study of fluids at rest and fluid dynamics, the study of fluids in motion.

The foundational axioms of fluid dynamics are the conservation laws:

- conservation of mass,

- conservation of linear momentum (also known as Newton's Second Law of Motion),

- conservation of energy (also known as First Law of Thermodynamics).

A solution to a fluid dynamics problem typically involves calculating various properties of the fluid, such as velocity, pressure, density and temperature as functions of space and time. Fluid dynamics has a wide range of applications, including calculating forces and moments on aircraft, determining the mass flow rate of petroleum through pipelines, predicting weather patterns, understanding nebulae in interstellar space and reportedly modelling fission weapon detonation. Some of its principles are even used in traffic engineering, where traffic is treated as a continuous fluid.

Calculations for large simulations of fluid flow can be mathematically complex and therefore several algorithms and numerical methods have been developed to solve these calculations. A modern discipline, called computational fluid dynamics (CFD), is devoted to this approach. The most common methods used in CFD are:

- Eulerian grid-based methods,

- Smoothed particle hydrodynamics methods,

- Vorticity-based methods,

- Lattice Boltzmann methods.

Computers are used to perform millions of calculations required to simulate the interaction of liquids and gases with surfaces defined by boundary conditions. In many 
cases, even with high-speed supercomputers, only approximate solutions can be achieved. Ongoing research, however, may yield software that improves the accuracy and speed of complex simulation scenarios such as transonic or turbulent flows.

\section{SIMULATION}

Nowadays the fluid flow simulation is an integral part of design and testing. It is used, for example, in aerospace (see Fig. 1), casting, coating, microfluidics and water flow simulations. There are several simulation software that deal with the issue of fluid flow simulation in the design, development and testing of the new devices. Two of them are Flow-3D [2] and ANSYS CFX [3].
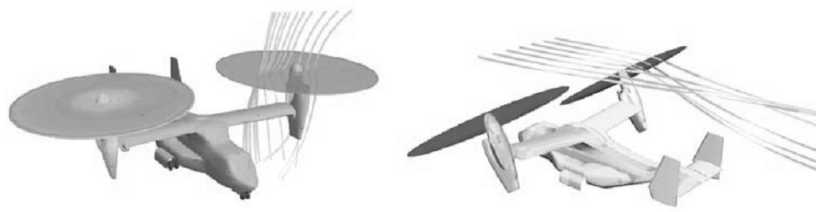

Fig. 1 Simulation of the changing tilt of the rotorcraft's wings while changing flight modes in ANSYS FLUENT [4]

Flow-3D is an advanced CFD model developed by Flow Science Inc. in Santa Fe, New Mexico. Flow-3D computes the three velocity components $(u, v, w)$ and pressure at the nodes of orthogonal Finite Difference Grid. Among the general-purpose CFD programs commercially available in the market, Flow-3D stands out for its capabilities intended for hydraulic engineering applications: it has excellent capabilities for modelling free surface flow; it can read topographic files in $(x, y, z)$ format; boundary conditions can by specified as a discharge hydrograph or water level hydrograph. Flow-3D has been used extensively to model structures such as spillways (Fig. 2), stilling basins, water intakes, fish ladders and similar instream structures.

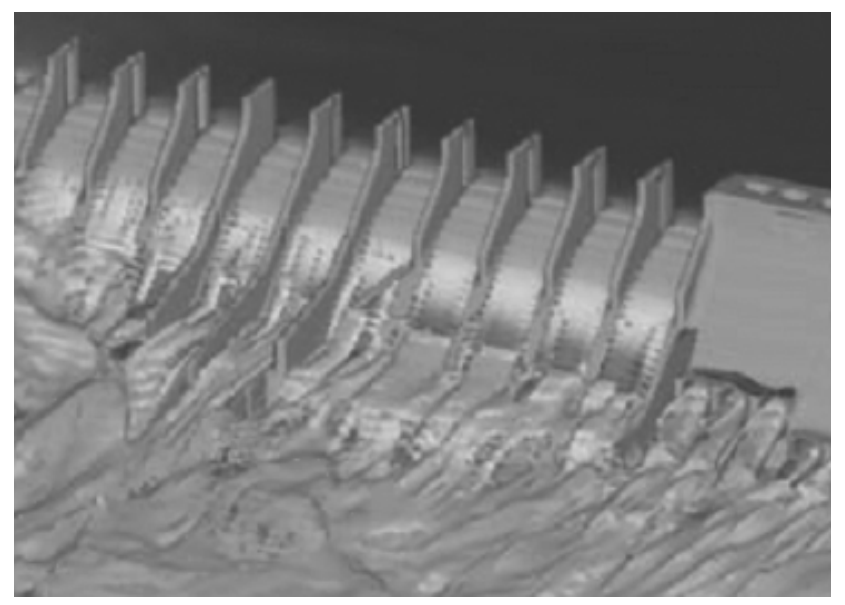

Fig. 2 Dam and spillway flow simulation [5]

As an interesting fact, Flow Science Inc. was founded by Dr. C.W. Hirt, who pioneered the Volume Of Fluid (VOF) method, a unique free surface tracking. The VOF is at present the best method available to simulate the movement of rapidly-varying water surfaces and it is used by all commercial CFD programs when modelling free surfaces. More about Flow-3D at [2].

ANSYS CFX is CFD modelling software developed by ANSYS. ANSYS CFX is based on finite volume method. In this method, the region of the interest is divided into small sub-regions, called control volumes. The equations are discretized and solved iteratively for each control volume. As a result an approximation of the each variable value at specific points throughout the domain can de obtained. In this way, one derives a full picture of the flow behaviour. Simulation by ANSYS CFX is shown in Fig. 3. More about ANSYS CFX at [3].

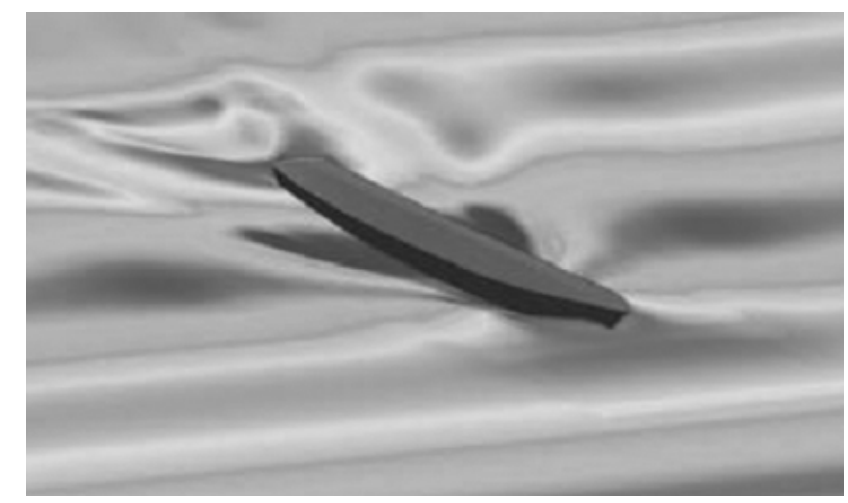

Fig. 3 Wave formation around a ship hull modelled with ANSYS CFX software [4]

\section{VISUALIZATION}

Fluid flow visualization process can be divided into two parts:

- virtual model creation,

- photorealistic visualization.

Also in visualization, simulation is used for creation of realistic fluid flow model, but the key difference is in the accuracy of simulation which is needed. That is, if a human observer is unable to identify by inspection whether a given animation is physically correct, the results are sufficient.

\subsection{Fluid flow model creation}

At present, there are several 3D modelling and visualization programs that allow fluid flow simulation. For example, these programs are:

- $\quad$ Autodesk 3ds Max [6],

- Autodesk Maya [7],

- Autodesk Softimage [8],

- Maxon Cinema 4D [9],

- NewTek LightWave 3D [10],

- Blender [11],

- $\quad$ Side Effects Software Houdini [12].

These programs use various methods for fluid flow simulation. For example Blender uses Lattice Boltzmann method.

There are also several plug-ins that can be used in mentioned programs. These plug-ins are used in fluid flow simulations, where simulation capabilities of 3D visualization software are insufficient. For example one of 
these plug-ins is Glu3D developed by 3DAlien [13]. This plug-in can be used in 3ds Max and Maya. For solving fluid flow simulations use smoothed particle hydrodynamics. Fig. 4 shows simulation made with Glu3D for 3ds Max.

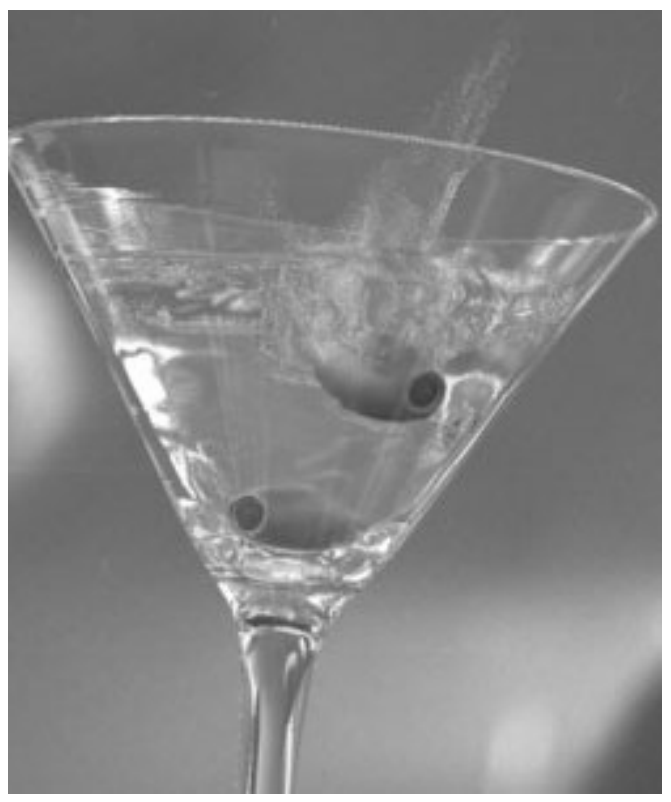

Fig. 4 Vermouth simulation made with Glu3D for 3ds Max [13]

Special cases are programs that can simulate fluid flow in prepared scenes and also can cooperate with 3D modelling programs via plug-ins. One of these programs is RealFlow [14] which cooperate via plug-ins with 3ds Max, Maya, Softimage, Cinema 4D, Houdini and LightWave 3D. In Fig. 5 is shown ocean waves simulated with RealFlow.

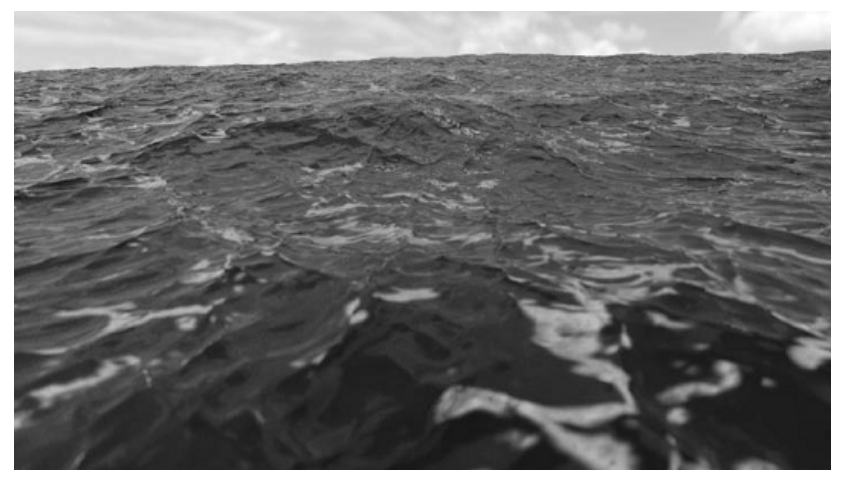

Fig. 5 Ocean waves simulated by RealFlow [15]

\subsection{Photorealistic visualization}

It is necessary for fluid flow realistic visualization that images and animations created in 3D modelling and visualization programs have a photorealistic quality. Rendering engines that generate photorealistic images and animation can already be part of 3D modelling software or can be added to this software via plug-ins. There are several rendering engines. Some of them are:

- YafaRay for Blender [16],

- Chaos Group V-Ray [17],

- mental images mental ray [18],

- $\quad$ SplutterFish Brazil [19],

- Cebas finalRender [20].

Fig. 6 shows example of failing drop animation, simulated in Blender and rendered in Yafaray.

\section{STEREOSCOPIC VISUALIZATION}

It is important how will be fluid flow simulations and visualizations displayed. They can be printed on a paper, shown on a monitor or projected on a screen with projector. But if stereoscopic visualization will be used for displaying, both simulation and visualization earn new dimension, a $3 \mathrm{rd}$ dimension. There are several ways how the stereoscopy can be implemented.

One of them is known as anaglyph. It has become quite a popular stereoscopic method, since it only requires usage of very cheap red-cyan glasses. The anaglyph is a composition of a red channel from the left image and green and blue channels (together creating a "cyan channel") from the right image. When looking at the anaglyph through red-cyan glasses, the left eye can only see the red part of the image and the right eye the rest.

Another one is stereoscopy based on light polarization. It requires two projectors with the ability to project polarized light and special polarized glasses. Through the glasses, the left eye can see only the projection from one projector and the right eye from the other one [21].

One such a system was constructed at DCI FEEI TU of Košice (see Fig. 7). This system uses a 90 degrees polarization and consists from these parts:

- pair of projectors with polarizing filter,

- polarized glasses,

- special projection screen,

- $\quad$ special mouse called space mouse for navigation in $3 \mathrm{D}$ scene,

- PC with special visualization software called SuperEngine.

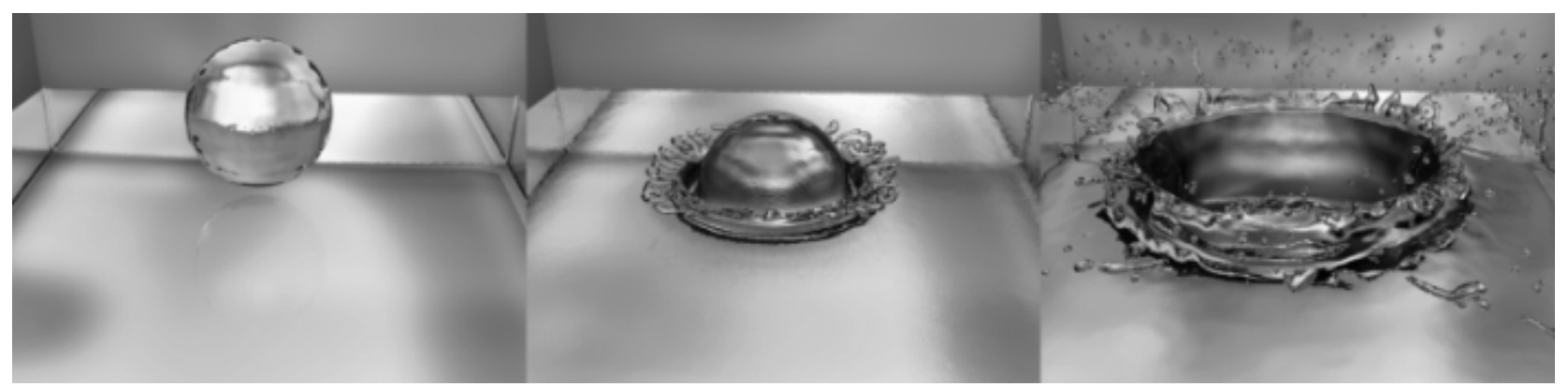

Fig. 6 Animation of a falling drop, simulated in Blender and rendered in YafaRay 
This visualization software can handle up to 2 times 3 millions of polygons per visualized scene, supports network rendering and one visualized scene can be accessed by two or more people from different places through network or internet. Scene in SuperEngine can be started by batch file or by Control Console program. In this console, scenes can be loaded and triggered on the fly. The main advantage of using Control Console is faster scenes scripting (SuperEngine use Ruby scripting language [22]), because no time is wasted with SuperEngine restarting.

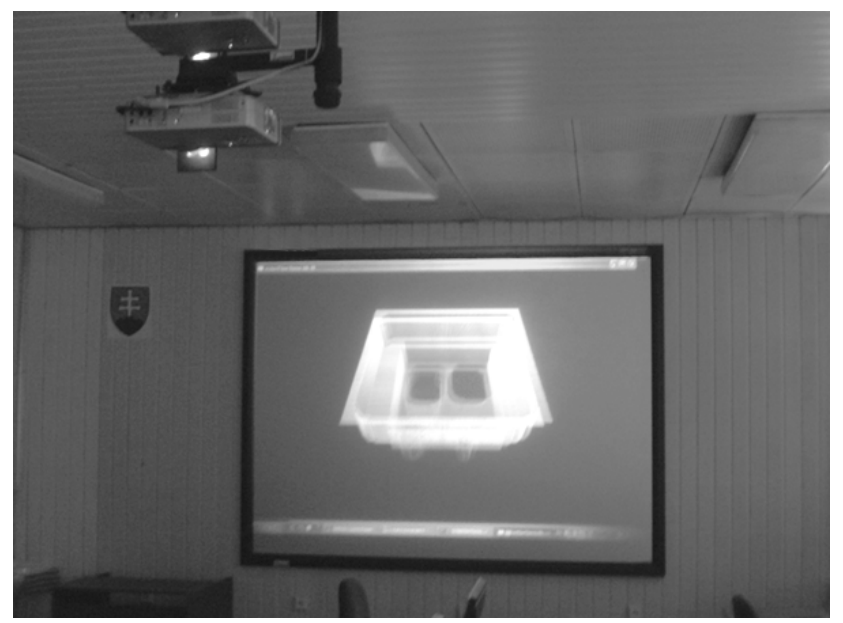

Fig. 7 Stereoscopic visualization of water flow with stereoscopic system constructed at DCI FEEI TU of Košice

\section{WATER INFLOW/DRAINAGE SIMULATION}

Also DCI FEEI TU of Košice has been working on water flow simulation issue. Result of this work was a water inflow/drainage simulation program (simulation output of this program with stereoscopic visualization is shown at Fig. 7). Simulation, in this program, has two phases: preparation phase and calculation phase.

\subsection{Preparation phase}

Terms used in preparation phase:

- Height map - represents simulated area,

- Height point - represents map height at certain coordinates (positive number),

- Layer - part of terrain with the same height. Individual coordinates of layer are formed by numbers 0 or 1.0 if height point is smaller than layer height. 1 if height point is bigger or same as layer height.

- Water area - part of layer, where is water (layer part where are 0$)$, bounded with area of 1 .

In preparation phase is a simulated area height map (Fig. 8) divided into layers. In these layers water areas are marked and their capacities are calculated. Capacity of one map cell is calculated using equation:

$$
\text { one cell capacity = one cell area } \times \text { layer height }
$$

These capacities are used in calculation phase for water inflow/drainage simulation.

\begin{tabular}{|l|l|l|l|l|l|l|l|l|l|}
\hline 4 & 4 & 4 & 4 & 4 & 4 & 4 & 4 & 4 & 4 \\
\hline 4 & 3 & 3 & 3 & 3 & 3 & 3 & 3 & 3 & 4 \\
\hline 4 & 3 & 3 & 3 & 3 & 2 & 2 & 2 & 3 & 4 \\
\hline 4 & 3 & 2 & 2 & 3 & 2 & 1 & 2 & 3 & 4 \\
\hline 4 & 3 & 2 & 2 & 3 & 2 & 1 & 2 & 3 & 4 \\
\hline 4 & 3 & 2 & 2 & 3 & 2 & 1 & 2 & 3 & 4 \\
\hline 4 & 3 & 2 & 2 & 3 & 2 & 1 & 2 & 3 & 4 \\
\hline 4 & 3 & 2 & 2 & 3 & 2 & 2 & 2 & 3 & 4 \\
\hline 4 & 3 & 3 & 3 & 3 & 3 & 3 & 3 & 3 & 4 \\
\hline 4 & 4 & 4 & 4 & 4 & 4 & 4 & 4 & 4 & 4 \\
\hline
\end{tabular}

Fig. 8 Simple simulated area height map $(10 \times 10)$

Layer 1 starts at height 1 and continue to height 2, layer 2 (Fig. 9) starts at height 2 and continue to height 3 and so on. In this case the height map can be divided into 4 layers.

Layer 1 has one water area with capacity of 4 (one cell capacity in this example is 1). Layer 2 has two water areas. Left one, with capacity of 8 and right one, with capacity of 18 (Fig. 9). Layer 3 has one area with capacity of 64 and layer 4 has also one water area with capacity of 100. Fig. 10 shows relationship between water areas.

\begin{tabular}{|l|l|l|l|l|l|l|l|l|l|}
\hline 1 & 1 & 1 & 1 & 1 & 1 & 1 & 1 & 1 & 1 \\
\hline 1 & 1 & 1 & 1 & 1 & 1 & 1 & 1 & 1 & 1 \\
\hline 1 & 1 & 1 & 1 & 1 & 0 & 0 & 0 & 1 & 1 \\
\hline 1 & 1 & 0 & 0 & 1 & 0 & 0 & 0 & 1 & 1 \\
\hline 1 & 1 & 0 & 0 & 1 & 0 & 0 & 0 & 1 & 1 \\
\hline 1 & 1 & 0 & 0 & 1 & 0 & 0 & 0 & 1 & 1 \\
\hline 1 & 1 & 0 & 0 & 1 & 0 & 0 & 0 & 1 & 1 \\
\hline 1 & 1 & 0 & 0 & 1 & 0 & 0 & 0 & 1 & 1 \\
\hline 1 & 1 & 1 & 1 & 1 & 1 & 1 & 1 & 1 & 1 \\
\hline 1 & 1 & 1 & 1 & 1 & 1 & 1 & 1 & 1 & 1 \\
\hline
\end{tabular}

Fig. 9 Layer 2 with two water areas

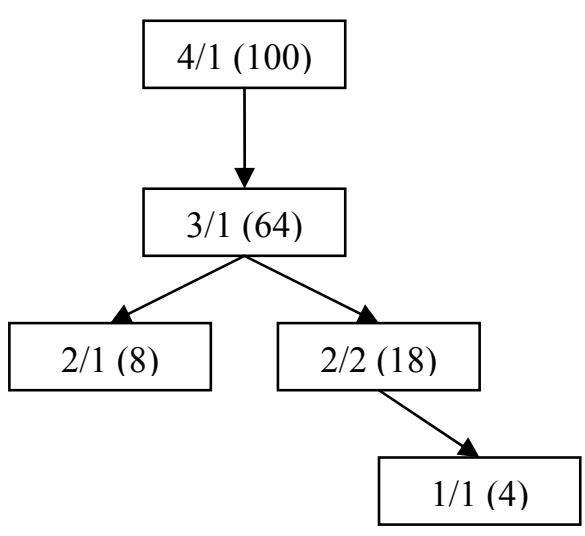




\subsection{Calculation phase}

Before adding/removing water to/from map it is important to create a fill table (see Table 1), which stores information about filling of individual water areas.

Table 1 Fill table

\begin{tabular}{|c|c|c|c|c|}
\hline & \multicolumn{2}{|c|}{ Own } & \multicolumn{2}{c|}{ Total } \\
\hline Water area & Capacity & Fill & Capacity & Fill \\
\hline $1 / 1$ & 4 & 0 & 4 & 0 \\
\hline $2 / 1$ & 10 & 0 & 10 & 0 \\
\hline $2 / 2$ & 18 & 0 & 22 & 0 \\
\hline $3 / 1$ & 64 & 0 & 100 & 0 \\
\hline $4 / 1$ & 100 & 0 & 200 & 0 \\
\hline
\end{tabular}

Algorithm of adding water to map is shown on following example, in which 50 water units are added to coordinate $[7,5]([0,0]$ is upper left corner). First step is to find the lowest water area, to which coordinate belongs (water area 1/1). Second step is to test if there is water sub-area that has free water capacity (in this case, it does not exist). Third step is to find how much water capacity is free in current water area (free capacity is 4 ). 4 water units are added to water area 1/1, 46 units left. Table is actualized (see Table 2).

Table 2 Updated fill table

\begin{tabular}{|c|c|c|c|c|}
\hline & \multicolumn{2}{|c|}{ Own } & \multicolumn{2}{c|}{ Total } \\
\hline Water area & Capacity & Fill & Capacity & Fill \\
\hline $1 / 1$ & 4 & 4 & 4 & 4 \\
\hline $2 / 1$ & 10 & 0 & 10 & 0 \\
\hline $2 / 2$ & 18 & 0 & 22 & 4 \\
\hline $3 / 1$ & 64 & 0 & 100 & 4 \\
\hline $4 / 1$ & 100 & 0 & 200 & 4 \\
\hline
\end{tabular}

Fourth step is to test if there is parent water area. If yes, algorithm continues to step 2. If no, algorithm ends. In case of this example, parent area for $1 / 1$ is area $2 / 2$, which has space for 18 water units. 18 water units are added to water area 2/2, 28 units left. Table is actualized (see Table 3).

Table 3 Updated fill table

\begin{tabular}{|c|c|c|c|c|}
\hline & \multicolumn{2}{|c|}{ Own } & \multicolumn{2}{c|}{ Total } \\
\hline Water area & Capacity & Fill & Capacity & Fill \\
\hline $1 / 1$ & 4 & 4 & 4 & 4 \\
\hline $2 / 1$ & 10 & 0 & 10 & 0 \\
\hline $2 / 2$ & 18 & 18 & 22 & 22 \\
\hline $3 / 1$ & 64 & 0 & 100 & 22 \\
\hline $4 / 1$ & 100 & 0 & 200 & 22 \\
\hline
\end{tabular}

Parent area for $2 / 2$ is area $3 / 1$, but this area has one sub-area (area $2 / 1$, with free capacity of 10 ). Therefore, 10 water units are added to $2 / 1$ and remaining 18 water units are added to $3 / 1$. Table is actualized (see Table 4). If water area has several sub-areas with free capacity, water will be distributed evenly to all sub-areas.
Table 4 Final fill table

\begin{tabular}{|c|c|c|c|c|}
\hline & \multicolumn{2}{|c|}{ Own } & \multicolumn{2}{c|}{ Total } \\
\hline Water area & Capacity & Fill & Capacity & Fill \\
\hline $1 / 1$ & 4 & 4 & 4 & 4 \\
\hline $2 / 1$ & 10 & 10 & 10 & 10 \\
\hline $2 / 2$ & 18 & 18 & 22 & 22 \\
\hline $3 / 1$ & 64 & 18 & 100 & 50 \\
\hline $4 / 1$ & 100 & 0 & 200 & 50 \\
\hline
\end{tabular}

Algorithm for water removing from map is similar to adding algorithm. Water removing is shown on another example, in which 40 water units are removed from coordinate [7,5] (starting fill table for this example is Table 4). First step is to find the lowest water area, to which coordinate belongs (water area 1/1). Second step is to test if there is a parent water area, which has water (area $2 / 2$ ). This step is repeated until top water area is founded (area 3/1). This area has 18 water units that are removed (see Table 5), 22 water units left.

Table 5 Updated fill table

\begin{tabular}{|c|c|c|c|c|}
\hline & \multicolumn{2}{|c|}{ Own } & \multicolumn{2}{c|}{ Total } \\
\hline Water area & Capacity & Fill & Capacity & Fill \\
\hline $1 / 1$ & 4 & 4 & 4 & 4 \\
\hline $2 / 1$ & 10 & 10 & 10 & 10 \\
\hline $2 / 2$ & 18 & 18 & 22 & 22 \\
\hline $3 / 1$ & 64 & 0 & 100 & 32 \\
\hline $4 / 1$ & 100 & 0 & 200 & 32 \\
\hline
\end{tabular}

In the next step, 18 units of water are removed from area $2 / 2$, which is a sub-area of $3 / 1$. Water is removed only from related water area, not from area $2 / 1$ (see Table 6). 4 water units left.

Table 6 Updated fill table

\begin{tabular}{|c|c|c|c|c|}
\hline & \multicolumn{2}{|c|}{ Own } & \multicolumn{2}{c|}{ Total } \\
\hline Water area & Capacity & Fill & Capacity & Fill \\
\hline $1 / 1$ & 4 & 4 & 4 & 4 \\
\hline $2 / 1$ & 10 & 10 & 10 & 10 \\
\hline $2 / 2$ & 18 & 0 & 22 & 4 \\
\hline $3 / 1$ & 64 & 0 & 100 & 14 \\
\hline $4 / 1$ & 100 & 0 & 200 & 14 \\
\hline
\end{tabular}

In the last step, last 4 units are removed from area $1 / 1$, which is sub-area of $2 / 2$ (see Table 7 ).

Table 7 Final fill table (water removing)

\begin{tabular}{|c|c|c|c|c|}
\hline & \multicolumn{2}{|c|}{ Own } & \multicolumn{2}{c|}{ Total } \\
\hline Water area & Capacity & Fill & Capacity & Fill \\
\hline $1 / 1$ & 4 & 0 & 4 & 0 \\
\hline $2 / 1$ & 10 & 10 & 10 & 10 \\
\hline $2 / 2$ & 18 & 0 & 22 & 0 \\
\hline $3 / 1$ & 64 & 0 & 100 & 10 \\
\hline $4 / 1$ & 100 & 0 & 200 & 10 \\
\hline
\end{tabular}




\section{APLICATIONS}

There are many projects, applications and solutions in which the fluid flow simulation and visualization can be used. In this section several of them will be mention.

\subsection{Terrain modelling}

In the Interactive Terrain Modeling Using Hydraulic Erosion [23] interactive physics-based modeling of terrains is presented. For terrain modeling is used water, which is the most important geomorphologic factor (water interacts with soils in the form of hydraulic erosion). Two hydraulic erosion algorithms for running water are used. Areas where the motion is slow become more eroded by the dissolution erosion (see Fig. 11), whereas in the areas with faster motion, the force-based erosion prevails. Also when the water under-erodes certain areas, slippage takes effect and the river banks fall into the water.

Interactive terrain modeling provides a wide variety of erosion-based modeling features such as forming rivers, drying flooded areas, rain, interactive manipulation with rivers, spring, adding obstacles into the water, etc.

More about interactive terrain modeling at [23].
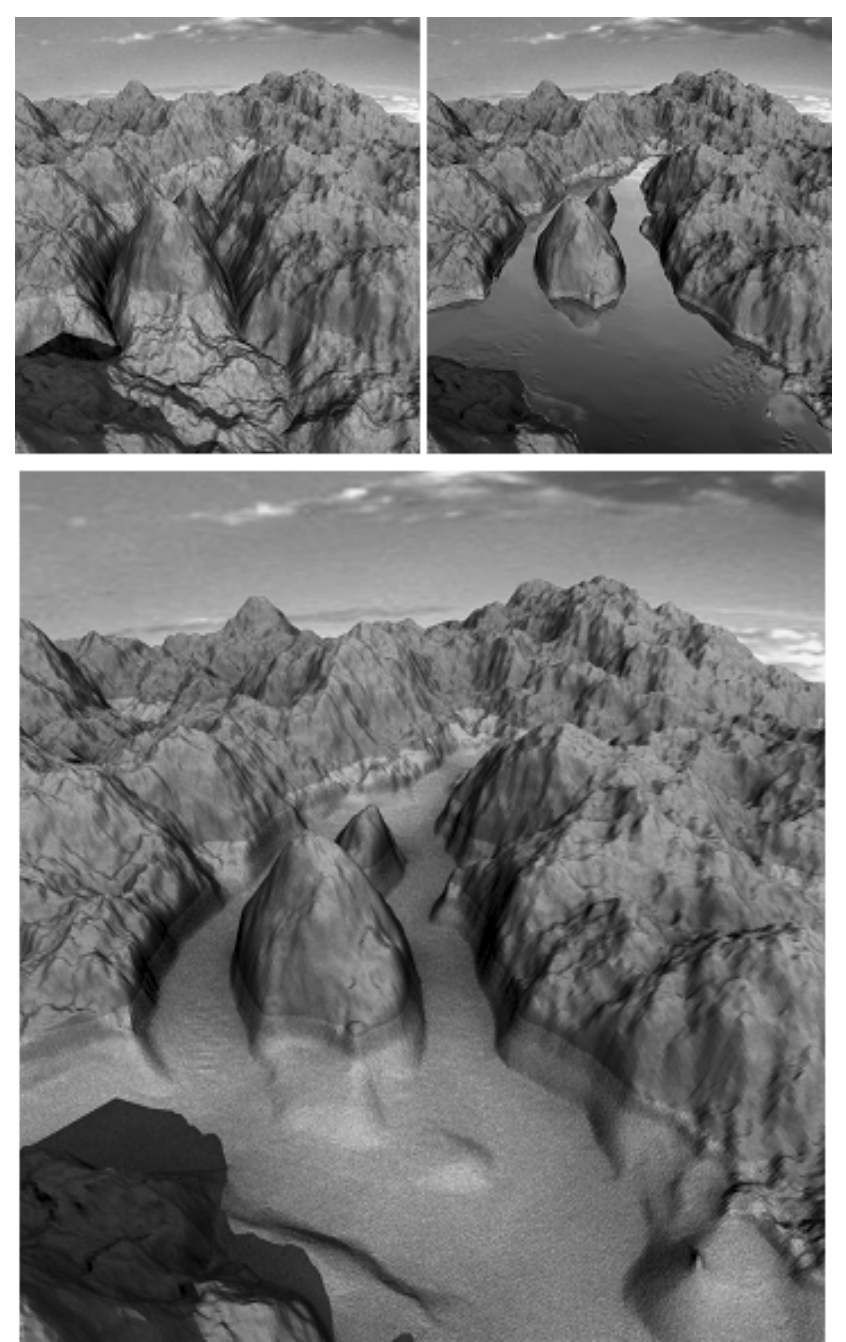

Fig. 11 Dissolution-based erosion softens the river bed and erodes the banks (Rendered using Mental Ray) [23]

\subsection{Hydro plant designing}

Manitoba Hydro used Flow-3D in design of Keeyask station. It has found that CFD modelling offers multiple benefits for planning the construction and operation of the Keeyask station. It is possible to quickly test various alternatives, providing a very cost-effective means to optimize the overall hydraulic design of the project. It is also possible to use CFD analysis to evaluate complicated design issues very early in the design process.

Also in design process were combined FLOW-3D simulations with scale-model testing. This combination offered an iterative path to improving the validity of both design options. Further, the simulation lets users easily and quickly extracts velocity, water level, and flow rates anywhere within the CFD model domain, as opposed to the limited values that could practicably be obtained with physical gauges and time-lapse photography.

Fig. 12 shows comparison of water velocities computed in the computational fluid dynamics simulations (left) with those measured during operation of the physical model (right). Comparison shows good agreement between the two approaches.

More about this project at [24].

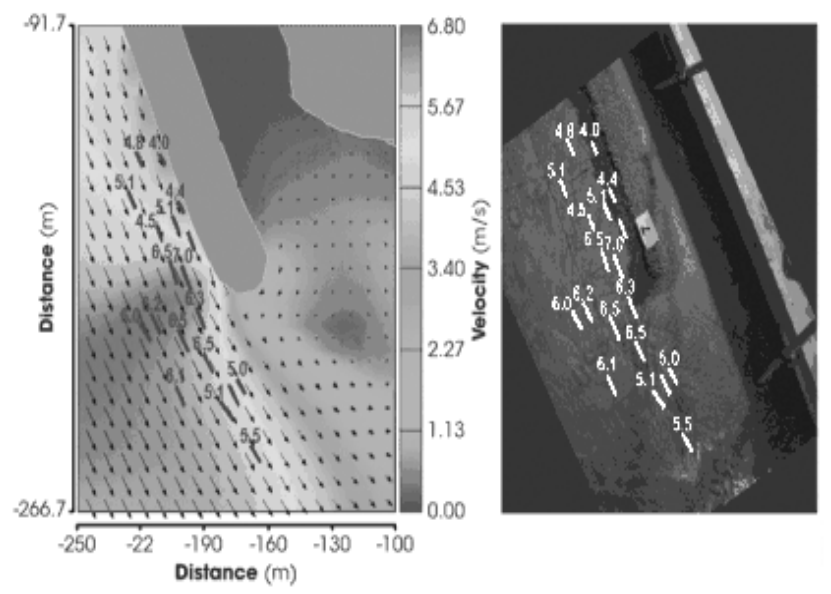

Fig. 12 Water velocity comparison [24]

\subsection{Improving a fish passage design}

Using FLOW-3D, AECOM Tecsult inc. was able to improve a fish passage design that allows sturgeon to successfully navigate the ladder without using physical modelling.

A fish passage was built in 2005-2006 by SEBJ (Hydro-Québec) on the Eastmain River in James Bay, Quebec, Canada. Follow-up studies conducted in 2006 and 2007 showed an unsuccessful use of the fish passage by sturgeon, while other species of fish were able to climb the ladder. After redesign of the fish passage, studies in summer of 2008 showed that the sturgeons are successfully navigating the fish passage even during the high flow rates. Fig. 13 shows CFD simulation results merge with reality.

More about improving a fish passage design at [25]. 


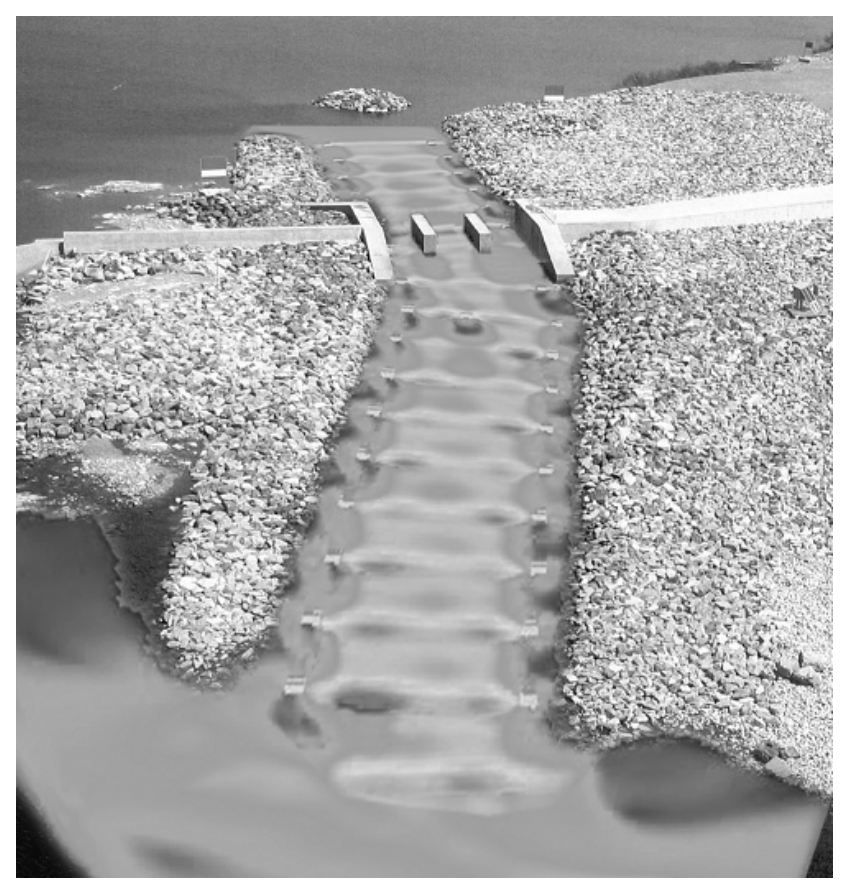

Fig. 13 CFD simulation results merge with reality [25]

\subsection{Entertainment and commercials}

At present many movies, commercials and animations use realistic simulations for creation of amazing visual effects (for example sea storms, tsunamis, floods, explosions and others).

RealFlow was used for visual effects creation in movies like Avatar, District 9, 2012, GI Joe and The Curious Case of Benjamin Button, as well as countless commercials, TV programs and game cinematics (see Fig. 14).

More about possibilities of RealFlow at [14].

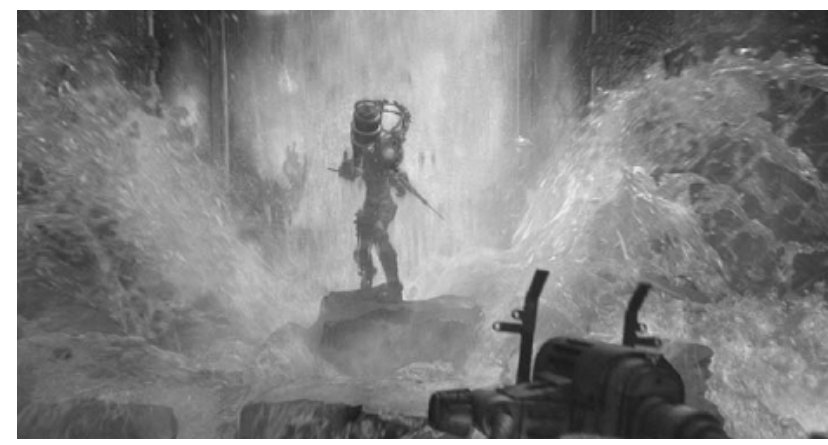

Fig. 14 Bioshock 2 cinematic - Blur Studios and BYVFX [15]

\section{CONCLUSION}

Fluid flow simulation and visualization is essential part of design and testing. It saves money and time, because errors can be found before physical prototype or final product is built. Especially, water flow simulation and visualization can save from large floods, which can kill many people and cause large material damage.

Simulation software mentioned in this paper can be used for design and testing of anti-flood barriers. For example, if planned anti-flood barrier can hold incoming flood waves. Also flood visualization helps crisis management to quickly respond to floods and their consequences. Presented stereoscopic visualization even more enhance advantages gained from using water flow simulation and visualization for design and testing.

Water simulation program presented in section 6 was developed by DCI FEEI TU of Košice. This program simulates water inflow/drainage and consists from two phases: preparation and calculation. In preparation phase layers with water areas are created from simulated area height map. These layers and water areas are used in calculation phase for simulation calculation. Future work on this program will be focused on:

- calculations acceleration,

- $\quad$ supporting GPU for simulation calculations.

\section{ACKNOWLEDGMENT}

This work is the result of the project implementation: Center of Information and Communication Technologies for Knowledge Systems (ITMS project code: 26220120020) supported by the Research \& Development Operational Program funded by the ERDF.

\section{REFERENCES}

[1] WHITE, F. M.: Fluid Mechanics, $5^{\text {th }}$ ed. New York: McGraw-Hill, November, 2002, 866 p., ISBN 0072402172.

[2] Flow-3D homepage, http://www.flow3d.com/

[3] ANSYS CFX homepage, http://www.ansys.com/products/fluid-dynamics/cfx/

[4] Fluid Analysis Solutions Brochure, http://www.ansys.com/assets/brochures/fluidanalysis-solutions-12.1.pdf

[5] Flow-3D Hydraulic brochure, http://www.flow3d.com/pdfs/brochures/FlowScience-Brochure-Hydraulics-WEB.pdf

[6] Autodesk 3ds Max homepage, http://usa.autodesk.com/adsk/servlet/pc/index?id=13 $567410 \&$ siteID $=123112$

[7] Autodesk Maya homepage, http://usa.autodesk.com/adsk/servlet/pc/index?id=13 577897\&siteID $=123112$

[8] Autodesk Softimage homepage, http://usa.autodesk.com/adsk/servlet/pc/index?id=13 571168\&siteID $=123112$

[9] Maxon Cinema 4D homepage, http://www.maxon.net/

[10] NewTek LightWave 3D homepage, http://www.newtek.com/lightwave/

[11] Blender homepage, http://www.blender.org/

[12] Side Effects Software Houdini homepage, http://www.sidefx.com/

[13] 3DAlien Glu3D homepage, http://3daliens.com/joomla/

[14] RealFlow homepage, http://realflow.com/ 
[15] RealFlow product sheet, http://realflow.com/pdf/rf5_product_sheet-final.pdf

[16] YafaRay homepage, http://www.yafaray.org/

[17] Chaos Group V-Ray homepage, http://www.chaosgroup.com/en/2/index.html

[18] mental images mental ray homepage, http://www.mentalimages.com/products/mentalray.html

[19] SplutterFish Brazil homepage, http://www.splutterfish.com/sf/WebContent/Index

[20] Cebas finalRender homepage,http:/www.cebas.com/

[21] SOBOTA, B. - SZABÓ, C. - ŠUBA, S.: The some problems by construction of multi-screen projection system, Journal of Computer Science and Control Systems, 2, 1, 2009, pp. 57-60, ISSN 1844-6043.

[22] Ruby scripting language homepage, http://www.ruby-lang.org/en/

[23] ŠŤAVA, O. - BENEŠ, B. - BRISBIN, M. KŘIVÁNEK, J.: Interactive terrain modeling using hydraulic erosion, SCA '08: Proceedings of the 2008 ACM SIGGRAPH/Eurographics Symposium on Computer Animation, Dublin, Ireland, pp. 201-210, 2008, ISBN 978-3-905674-10-1.

[24] SYDOR, K. M. - WATERMAN, P. J.: Engineering and Design: The Value of CFD Modeling in Designing a Hydro Plant, Hydro Review, Volume 29, Issue 6, September 2010, http://www.hydroworld.com/index/display/articledisplay/6247879386/articles/hydro-review/volume29/issue-6/articles/engineering-and-design-the-valueof-cfd-modeling-in-designing-a-hydro-plant.html

[25] Flow Science Case study Tescult, http://www.flow3d.com/pdfs/brochures/FlowScience-Case-Study-Tecsult.pdf

Received September 24, 2010, accepted January 12, 2011

\section{BIOGRAPHIES}

František Hrozek was born on 19.5.1985. In 2009 he graduated (MSc.) with honours at the Department of Computers and Informatics, Faculty of Electrical Engineering and Informatics at Technical University in Košice. Since 2009 he is a PhD student at the DCI at this university. His main scientific research is focusing on $3 \mathrm{D}$ interfaces of systems and computer graphics.

Branislav Sobota was born on 22.5.1967. In 1990 he graduated (MSc.) with honours at the Department of Computers and Informatics of the FEEI at Technical University in Košice. He defended his PhD. in 1999 and habilitation thesis in 2008 in the field of virtual reality and computer graphics. He is working as an associate professor at the Department of Computers and Informatics. His scientific research is focusing on computer graphics and virtual reality. 